\title{
Quantitative Trait Loci for Adult-Plant Resistance to Mycosphaerella graminicola in Two Winter Wheat Populations
}

\author{
P. Risser, E. Ebmeyer, V. Korzun, L. Hartl, and T. Miedaner
}

First and fifth authors: Universität Hohenheim, State Plant Breeding Institute (720), Stuttgart, Germany; second and third authors: KWS LOCHOW GmbH, Ferdinand-von-Lochow-Straße 5, D-29303 Bergen, Germany; and fourth author: Bavarian State Research Center for Agriculture, Institute of Crop Science and Plant Breeding, D-85354 Freising, Germany.

Current address of P. Risser: Südzucker AG Mannheim/Ochsenfurt, Marktbreiter Straße 74, D-97199 Ochsenfurt, Germany.

Accepted for publication 23 May 2011.

\begin{abstract}
Risser, P., Ebmeyer, E., Korzun, V., Hartl, L., and Miedaner, T. 2011. Quantitative trait loci for adult-plant resistance to Mycosphaerella graminicola in two winter wheat populations. Phytopathology 101:1209-1216.

Septoria tritici blotch (STB) is one of the most important leaf spot diseases in wheat worldwide. The goal of this study was to detect chromosomal regions for adult-plant resistance in large winter wheat populations to STB. Inoculation by two isolates with virulence to Stb6 and $S t b 15$, both present in the parents, was performed and STB severity was visually scored plotwise as percent coverage of flag leaves with pycnidia-bearing lesions. 'Florett'/'Biscay' and 'Tuareg'/'Biscay', each comprising a cross of a resistant and a susceptible cultivar, with population sizes of 316 and $269 \mathrm{~F}_{7: 8}$ recombinant inbred lines, respectively, were phenotyped across four and five environments and mapped with

centimorgans. Phenotypic data revealed significant $(P<0.01)$ genotypic differentiation for STB, heading date, and plant height. Entry-mean heritabilities $\left(h^{2}\right)$ for STB were 0.73 for 'Florett'/'Biscay' and 0.38 for 'Tuareg'/'Biscay'. All correlations between STB and heading date as well as between STB and plant height were low $(r=-0.13$ to -0.20$)$. In quantitative trait loci (QTL) analysis, nine and six QTL were found for STB ratings explaining, together, 55 and $51 \%$ of phenotypic variation in 'Florett'/'Biscay' and 'Tuareg'/'Biscay', respectively. Genotype-environment and QTL-environment interactions had a large impact. Two major QTL were detected consistently across environments on chromosomes 3B and 6D from 'Florett' and chromosomes 4B and 6B from 'Tuareg', each explaining 12 to $17 \%$ of normalized adjusted phenotypic variance. These results indicate that adult-plant resistance to STB in both mapping populations was of a quantitative nature.
\end{abstract} amplified fragment length polymorphism, diversity array technology, and simple sequence repeat markers covering polymorphic regions of $\approx 1,340$
Additional key words: Triticum aestivum.
Septoria tritici blotch (STB), caused by Mycosphaerella graminicola (anamorph Septoria tritici), is one of the most important diseases in wheat (Triticum aestivum L.) worldwide, responsible for severe damage of the leaves and causing yield losses of 30 to $40 \%$ (14). Control of STB includes crop rotation, soil tillage, fungicide application, and cultivation of resistant cultivars. Some fungicides, including widely used strobilurins, are no longer effective due to mutations in the highly variable pathogen population of M. graminicola (34). Therefore, resistance breeding provides a promising strategy for controlling the disease. In the wheat-M. graminicola pathosystem, both qualitative, isolatespecific, vertical resistance depending on major genes and quantitative, isolate-nonspecific, horizontal resistance with polygenic inheritance have been reported. Until now, 13 major genes for resistance to STB (Stb1 to $S t b 12$ and $S t b 15$ ) have been mapped $(10,15)$. Stb6 and $S t b 15$ are the most common resistance genes in European germplasm (4). Isolate-specific resistance genes could be effective at seedling and adult-plant stage (3) or just at seedling and not at adult-plant stage (20), depending on the gene. Given the high diversity within local populations of $M$. graminicola (41), quantitative resistances should be favored (23). Until now,

Corresponding author: T. Miedaner; E-mail address: miedaner@uni-hohenheim.de

* The $\boldsymbol{e}$-Xtra logo stands for "electronic extra" and indicates that the online version contains one supplementary table and one supplementary figure.

doi:10.1094/PHYTO-08-10-0203

This article is in the public domain and not copyrightable. It may be freely reprinted with customary crediting of the source. The American Phytopathological Society, 2011. little is known about the inheritance of adult-plant resistance to STB in the field. Three previous studies about genetic mapping for STB resistance included small populations of 65 to 106 progenies and one to three environments $(7,13,32)$. A very recent study concentrated on seedling resistance (42). Moreover, Simón et al. (32) detected only two isolate-specific loci. In this study, two biparental recombinant inbred line (RIL) populations with a high number of progenies $(n>250)$ were developed to analyze the inheritance of adult-plant resistance to STB by inoculation in field trials across four to five environments.

\section{MATERIALS AND METHODS}

Plant material. In total, 316 and $269 \mathrm{~F}_{7: 8}$ RILs were developed from two crosses between 'Florett' and 'Biscay' and 'Tuareg' and 'Biscay', respectively. Test entries were derived from $\mathrm{F}_{7}$ lines and tested after a seed multiplication as $\mathrm{F}_{8}$ bulks. 'Florett' (PBIS9582/Cortez) from RAGT and 'Tuareg' (Kris/Dekan) from Nordsaat are the resistant parents containing Stb6 and Stb15 or Stb6 alone, respectively (26). 'Biscay' (CPB79/Hussar) from KWS LOCHOW is the common susceptible parent without any known racespecific resistance genes. All three cultivars are high-yielding elite parents containing the dwarfing allele Rht-Dlb. The two progenies have been kindly provided by KWS LOCHOW.

Isolates, inoculum production, and inoculation. Both mapping populations were inoculated with a mixture of two German isolates (BAZ 6/1/04 and BAZ 8/8/04), kindly provided by JuliusKühn-Institut, Quedlinburg, Germany. Both isolates were virulent to Stb6 and Stb15 as tested in a seedling test by G. J. Kema, Wageningen, The Netherlands as described by Kema et al. (19). 
Inoculum was produced at the Institute of Crop Science and Plant Breeding, Freising, Germany, from sporulating cultures of M. graminicola and grown on yeast malt agar (YMA) for 3 to 5 days under ultraviolet (UV) light for $16 \mathrm{~h}$ per day at $18^{\circ} \mathrm{C}$ and $8 \mathrm{~h}$ per night at $12^{\circ} \mathrm{C}$. This starter culture was used to produce large amounts of inoculum for field trials. Inoculum was prepared by inoculating $150 \mathrm{ml}$ of liquid yeast-malt-glucose medium (4 g of yeast, $4 \mathrm{~g}$ of malt, and $4 \mathrm{~g}$ of glucose in 1 liter of distilled water) in 300-ml Erlenmeyer flasks with fresh M. graminicola spores from agar plates. Several flasks per isolate were incubated for 3 to 5 days in reciprocal shakers $(175 \mathrm{rpm})$ under natural light in the greenhouse at 18 to $20^{\circ} \mathrm{C}$. The resultant spore suspensions were concentrated into $200-\mathrm{ml}$ tubes using separating funnels. The concentrate was stored in freezers at $-20^{\circ} \mathrm{C}$ until $24 \mathrm{~h}$ before inoculation. At each location, the inoculum was adjusted to a density of $5 \times 10^{6}$ spores $/ \mathrm{ml}$ as determined by hemacytometer counts (Neubauer improved, depth $0.1 \mathrm{~mm}, 0.0025 \mathrm{~mm}$; Laboroptik GmbH, Germany).

All trials were inoculated once at growth stage EC39-55 (39), after late genotypes' flag leaves had been fully unrolled. The populations were inoculated using a tractor-mounted sprayer. Inoculation was done after rainfall and during cloudy weather conditions so that moisture was retained on the leaf surface for several hours. At Freising 2009, mist irrigation was used after inoculation to enhance infection frequency.

Field trials. 'Florett'/'Biscay' and 'Tuareg'/'Biscay' were evaluated in five and four environments (location-year combinations), respectively. Trials with both mapping populations were conducted at Freising (FRE) (latitude $\mathrm{N} 48.45^{\circ}$, longitude $\mathrm{E}$ $11.72^{\circ}, 448 \mathrm{~m}$ above sea level [a.s.1.], $7.5^{\circ} \mathrm{C}$ mean annual temperature, $775 \mathrm{~mm}$ mean annual precipitation) and Wohlde (WOH) (latitude $\mathrm{N} 52.80^{\circ}$, longitude $\mathrm{E} 9.98^{\circ}, 80 \mathrm{~m}$ a.s.l., $8.8^{\circ} \mathrm{C}$ mean annual temperature, $753 \mathrm{~mm}$ mean annual precipitation) in 2008 and at FRE 2009. Additionally, 'Florett'/'Biscay' was tested at Stuttgart-Hohenheim $\left(\mathrm{HOH}\right.$, latitude $\mathrm{N} 48.80^{\circ}$, longitude E $9.20^{\circ}$, $400 \mathrm{~m}$ a.s.1., $8.5^{\circ} \mathrm{C}$ mean annual temperature, $685 \mathrm{~mm}$ mean annual precipitation) in 2008 and Oberer Lindenhof (OLI, latitude $\mathrm{N} 48.52^{\circ}$, longitude $\mathrm{E} 9.05^{\circ}, 700 \mathrm{~m}$ a.s.1., $6.6^{\circ} \mathrm{C}$ mean annual temperature, $960 \mathrm{~mm}$ mean annual precipitation) in 2009. 'Tuareg'/'Biscay' was additionally tested at OLI 2008.

The populations were grown together with each of five replicated entries of the parental lines as $\alpha$-design with two replications at each location adjacent to each other. Each entry was sown in sets of two $1-\mathrm{m}$ rows with $\approx 40$ to 60 kernels per row.

In all field trials, STB rating, heading date, and plant height were evaluated. STB severity was visually scored plotwise as percent coverage of flag leaves with lesions bearing pycnidia. Flag leaves of double rows were assessed three times at an interval of 4 to 7 days, starting from $\approx 30$ days after inoculation. The arithmetic mean of two scorings, representing middle and end of disease development, was used in the following analyses. Heading date was scored as days after 1st January, when $50 \%$ of spikes of a plot had emerged. Plant height was measured from the soil surface to the middle of the spike on the main tillers.

Marker analysis and genetic mapping. In order to construct genetic maps with broad coverage enabling quantitative trait loci (QTL) mapping, we used a combination of amplified fragment length polymorphism (AFLP), diversity array technology (DArT), and simple sequence repeat (SSR) markers. AFLP markers were generated using PstI/MseI restriction enzymes and 45 selective primer combinations by the Institute of Crop Science and Plant Breeding, Freising, Germany. DArT markers were analyzed by the company Triticarte (Triticarte P/L, Yarralumla, Australia; http://www.triticarte.com.au). We used Triticarte service wheat PstI (TaqI) v2.3 (2,500 markers) in 'Tuareg'/'Biscay' and v2.5 (5,000 markers) in 'Florett'/'Biscay'. Akbari et al. (1) described an integrated map for a cross between the wheat 'Cranbrook' and 'Halberd' using restriction fragment length polymorphism, SSR,
AFLP, sequence-tagged microsatellite, and DArT markers that were used as a reference map (Supplementary Figure 1). KWS LOCHOW (Dr. Viktor Korzun) provided a total of 263 SSR anchor markers with 3 to 5 markers per chromosome to facilitate assignment of linkage groups to chromosomes. These markers are publicly available (Supplementary Figure 1) and were preselected for a maximal polymorphism in German wheat materials.

Genetic linkage maps were generated using JoinMap 3.0 (38) assuming Haldane's mapping function (16) as an essential prerequisite for composite interval mapping (CIM) as outlined by Zeng (40). Markers were assigned to linkage groups at logarithm of odds (LOD) $\geq 3.0$ with a maximum recombination fraction of 0.4. Because of obvious clustering of markers, markers without additional information within 1 centimorgan $(\mathrm{cM})$ were deleted. Clustered DArT markers were deleted first, followed by AFLP. SSR markers remained in the map. In summary, we started with a larger set of polymorphic markers and ended with a subset of these as mapped markers used for QTL analysis. Abbreviations of DArT markers were used as provided by Triticarte, with wPt and tPt referring to markers documented in the wheat and triticale map, respectively. AFLP loci were designated according to the standard list provided by the manufacturer (KeyGene Inc., Wageningen, The Netherlands) (21). For example, marker locus XP6451-190 refers to a fragment of $\approx 190 \mathrm{bp}$ amplified with primer combination P64/M51.

Data analysis. Analyses were based on single-plot values. Estimation of variance components was done using PLABSTAT (35). Residuals of mapping populations did not follow normal distribution. Logit and arcsin transformations were applied but did not improve the normality of the data. Therefore, untransformed data were used for analysis of variance (ANOVA) and QTL analysis. Lattice-adjusted means were calculated for genotypes in each environment and used for ANOVA. Analysis across environments was performed using a general linear model with genotype and environment effects, considering genotype as random. Entrymean heritability $\left(h^{2}\right)(22)$ was calculated by PLABSTAT with

$$
h^{2}=\frac{\sigma_{g}^{2}}{\sigma_{g}^{2}+\frac{\sigma_{g e}^{2}}{E}+\frac{\sigma^{2}}{E R}}
$$

where $\sigma_{g}^{2}$ denotes the genotypic variance, $\sigma_{g e}^{2}$ the genotype-environment interaction variance, $\sigma^{2}$ the error variance, and $E$ and $R$ are the numbers of environments and replications per environment, respectively.

QTL analysis was performed using CIM with PLABQTL (36). For detection of QTL, the LOD threshold was set to 3.0. Critical LOD scores were determined in all populations based on 1,000 permutations as recommended by Churchill and Doerge (11) at the 0.1 probability level. Additionally, fivefold cross validation was applied to determine the magnitude of bias of phenotypic variance $\left(R^{2}\right)$ explained by detected QTL. The entire data set (DS) was split into five genotypic subsamples. Means from four out of five subsamples served as estimation set (ES) for QTL detection, localization, and estimation of genetic effects. The remaining subset forms the test set (TS) in which predictions derived from the ES are tested for their validity by correlating predicted and observed data. By permutating the respective subsets used for the ES and TS, five different cross-validation runs were possible (37). In this study, fivefold cross validation with 200 replicated runs was used. Detected QTL are presented with genome position, flanking markers, distance to next marker, confidence interval (CI), and normalized adjusted $R^{2}\left(\mathrm{n} R_{\text {adj }}^{2}\right.$. The $95 \%$ CI was calculated after Darvasi and Soller (12). $R^{2}$ was adjusted $\left(R^{2}\right.$ adj $)$ to get a more adequate estimation of explained phenotypic variance (17), and was normalized ( $\mathrm{n} R_{\text {adj }}$ ) so that the sum across detected QTL is equal to model $R_{\text {adj }}^{2}$ (40). In this study QTL was declared major if it explained $>10 \%$ of $R_{\text {adj. }}^{2}$ In the final simultaneous fit, the detected QTL and their positions were used to obtain esti- 
mates of additive effects. These effects were calculated for each environment illustrating QTL-environment (QTL-E) interaction. QTL-E interactions were tested for significance by a sequentially rejective Bonferroni $F$ test according to Bohn et al. (6).

\section{RESULTS}

Phenotypic data. Field trials revealed differentiation for STB rating, heading date, and plant height between the parents and within the two mapping populations. Both mapping populations showed a continuous distribution of mean STB rating averaged across environments (Fig. 1). Parental lines were located on either end of the distribution. ANOVA for STB revealed highly significant $(P<0.01)$ variance components of genotype $(\mathrm{G})$, environment $(\mathrm{E})$, and $\mathrm{G}-\mathrm{E}$ interaction (Table 1). 'Tuareg'/'Biscay' population had a considerably smaller genotypic variance but G$\mathrm{E}$ interaction and error variances similarly high to that of 'Florett'/'Biscay'. Accordingly, entry-mean heritability was low for 'Tuareg'/'Biscay' compared with 'Florett'/'Biscay'. Correlations between STB and heading date as well as between STB and plant height were negative and low $(r=-0.13$ to -0.20$)$ although significant $(P<0.01)$ for both populations.

Mapping data. For 'Florett'/'Biscay' and 'Tuareg'/'Biscay', 5,000 and 2,500 DArT markers, respectively, and 263 SSR markers per population were used for mapping. Polymorphism rate for DArT markers was 7.7 and $7.5 \%$ and that for SSR markers was 28 and $30 \%$, respectively. In total, the number of polymorphic markers was 609 for 'Florett'/'Biscay' and 384 for 'Tuareg'/'Biscay'. From these, 221 and 262 could be mapped for 'Florett'/'Biscay' and 'Tuareg'/'Biscay', respectively (Table 2). They provided maps with polymorphic regions spanning 1,341 and $1,327 \mathrm{cM}$ with an average interval distance of 2.3 and $3.6 \mathrm{cM}$, respectively. Total number of linkage groups amounted to 22 in 'Florett'/ 'Biscay' and 20 in 'Tuareg'/'Biscay'. Each of the linkage groups could be assigned to one of the chromosomes. In 'Tuareg'/ 'Biscay', chromosomes 3D and 6D were missing.

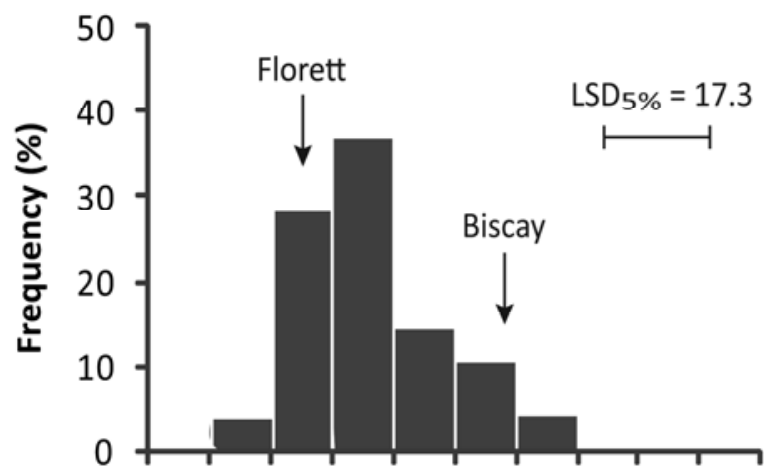

$10203040506070 \quad 8090100$

Flag leaf infection (\%)

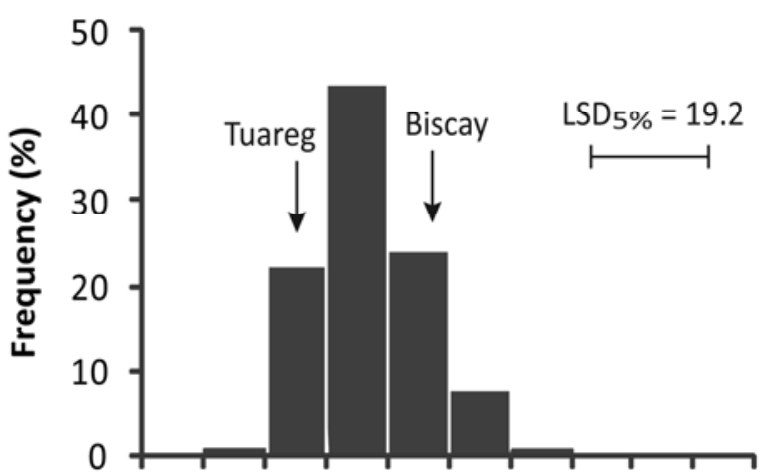

102030405060708090100 Flag leaf infection (\%)

Fig. 1. Histograms of Septoria tritici blotch rating (percent flag leaf area affected) across environments after inoculation. Mean rating of parents are indicated by an arrow. LSD $_{5 \%}=$ least significant difference at $P<0.05$.

TABLE 1. Estimates of variance components and heritabilities ( \pm standard error) for Septoria tritici blotch rating (percent flag leaf area affected) of two wheat populations evaluated in four and five environments after inoculation, respectively

\begin{tabular}{|c|c|c|c|c|c|c|c|c|c|}
\hline \multirow[b]{3}{*}{ Population } & \multicolumn{8}{|c|}{ Source of variation } & \multirow[b]{3}{*}{ Heritability } \\
\hline & \multicolumn{2}{|c|}{ Environment (E) } & \multicolumn{2}{|c|}{ Genotype (G) } & \multicolumn{2}{|c|}{$\mathrm{G} \times \mathrm{E}$} & \multicolumn{2}{|c|}{ Error } & \\
\hline & $\mathrm{DF}^{\mathrm{a}}$ & $\begin{array}{l}\text { Variance } \\
\text { components }\end{array}$ & $\mathrm{DF}$ & $\begin{array}{l}\text { Variance } \\
\text { components }\end{array}$ & DF & $\begin{array}{l}\text { Variance } \\
\text { components }\end{array}$ & DF & $\begin{array}{l}\text { Variance } \\
\text { components }\end{array}$ & \\
\hline 'Florett'/‘Biscay' & 4 & $172.6 * *$ & 315 & $104.3^{* *}$ & 1,260 & $143.8^{* *}$ & 1,525 & 49.8 & $0.73 \pm 0.02$ \\
\hline 'Tuareg'/'Biscay' & 3 & $151.7 * *$ & 268 & $28.7 * *$ & 804 & $140.9 * *$ & 1,012 & 49.5 & $0.38 \pm 0.06$ \\
\hline
\end{tabular}

${ }^{\text {a }} \mathrm{DF}=$ degrees of freedom; ** indicates $F$ test significant at $P<0.01$.

TABLE 2. Number of mapped amplified fragment length polymorphism (AFLP), diversity array technology (DArT), and simple sequence repeat (SSR) markers on chromosomes and genomes and total genome coverage in two wheat populations

\begin{tabular}{|c|c|c|c|c|c|c|c|c|c|c|}
\hline \multirow[b]{2}{*}{ Population, genome } & \multicolumn{7}{|c|}{ Chromosome } & \multirow[b]{2}{*}{ Total } & \multirow[b]{2}{*}{ Percent } & \multirow[b]{2}{*}{ Coverage $(\mathrm{cM})^{\mathrm{a}}$} \\
\hline & 1 & 2 & 3 & 4 & 5 & 6 & 7 & & & \\
\hline \multicolumn{11}{|l|}{ 'Florett'/'Biscay' } \\
\hline $\mathrm{D}$ & 10 & 18 & 2 & 5 & 10 & 3 & 4 & 52 & 23.5 & 331 \\
\hline Sum & $\cdots$ & $\ldots$ & $\ldots$ & $\ldots$ & $\ldots$ & $\ldots$ & $\ldots$ & $\ldots$ & $\ldots$ & 1,341 \\
\hline \multicolumn{11}{|l|}{ 'Tuareg'/'Biscay' } \\
\hline $\mathrm{D}$ & 12 & 19 & - & 5 & 13 & - & 10 & 59 & 22.5 & 327 \\
\hline Sum & $\ldots$ & $\ldots$ & $\ldots$ & $\ldots$ & $\ldots$ & $\ldots$ & $\ldots$ & $\ldots$ & $\ldots$ & 1,327 \\
\hline
\end{tabular}

${ }^{a}$ Genome coverage in centimorgans (cM). 
QTL analysis. In total, nine and six QTL were detected for STB in 'Florett'/'Biscay' and 'Tuareg'/'Biscay', respectively (Table 3). Critical LOD scores based on 1,000 permutations were 3.0 to 3.2 among the two mapping populations. Two major QTL $\left(\mathrm{n} R_{\text {adj }}^{2} \geq 10 \%\right.$ ) for resistance to STB were detected per population. Altogether, resistance QTL explained $\approx 50 \%$ of the total phenotypic variance (total $R_{\text {adj }}^{2}$ ). The majority of resistance QTL showed significant $(P<0.01)$ QTL-E interactions.

Because of the high QTL-E interaction, the additive effects of resistance QTL at each location are given in Table 4. Two major
QTL of 'Florett'/'Biscay' had a small additive effect at FRE and WOH 2008 but a high impact at HOH 2008 and OLI 2009. In the combined analysis across environments, the resistant alleles of the two major QTL reduced STB rating by 5.2 and 5.8\% flag leaf infection. Both susceptible and resistant parents, were donors of resistance alleles, although the susceptible 'Biscay' contributed only QTL with small effects. In 'Tuareg'/'Biscay', again, WOH 2008 contributed less to the total explained variance than the other two environments. The QTL derived from 'Biscay' had only a small effect at two of the four environments.

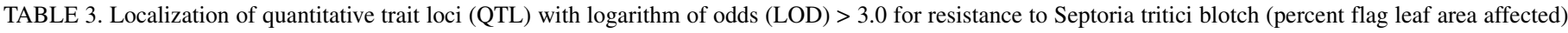
in two wheat populations (means across environments) ${ }^{\mathrm{a}}$

\begin{tabular}{|c|c|c|c|c|c|c|c|c|c|}
\hline \multirow[b]{2}{*}{ Population, QTL number } & \multirow[b]{2}{*}{ Chromosome } & \multirow[b]{2}{*}{ Pos. $(\mathrm{cM})^{\mathrm{b}}$} & \multicolumn{2}{|c|}{ Flanking marker ${ }^{\mathrm{c}}$} & \multirow[b]{2}{*}{ LOD } & \multirow[b]{2}{*}{$d(c M)^{d}$} & \multirow[b]{2}{*}{$\mathrm{CI}(\mathrm{cM})^{\mathrm{e}}$} & \multirow[b]{2}{*}{$\mathrm{n} R^{2}{ }_{\text {adj }}(\%)^{\mathrm{f}}$} & \multirow[b]{2}{*}{ QTL-Eg } \\
\hline & & & Left & Right & & & & & \\
\hline \multicolumn{10}{|l|}{ 'Florett'/'Biscay' $(n=301)$} \\
\hline 1 & $1 \mathrm{~A}$ & 44 & Xwmc0312 & XwPt-7030 & 4.4 & 0 & $27-56$ & 3.0 & $* *$ \\
\hline 2 & $1 \mathrm{~B}$ & 78 & XwPt-0260 & Xwmc0419 & 4.3 & 0 & $68-88$ & 2.9 & $* *$ \\
\hline 3 & $2 \mathrm{~B}$ & 4 & XP2553-222 & Xwmc0344 & 7.1 & 4 & $0-10$ & 4.8 & $* *$ \\
\hline 4 & $3 \mathrm{~B}$ & 60 & XP2553-237 & Xstb10 & 20.7 & 1 & $57-61$ & 12.6 & $* *$ \\
\hline 5 & 4B & 6 & XP1754-147 & XwPt-8092 & 14.7 & 1 & $2-10$ & 9.3 & $* *$ \\
\hline 6 & $5 B$ & 2 & Xgwm0408 & XwPt-4577 & 3.4 & 0 & $0-19$ & 2.3 & $* *$ \\
\hline 7 & $6 \mathrm{D}$ & 16 & Xgwm0469 & Xcfd0013 & 19.4 & 0 & $13-16$ & 11.9 & $* *$ \\
\hline 8 & 7A & 36 & Xbarc0108 & Xwmc0009 & 7.6 & 0 & $30-42$ & 5.1 & $* *$ \\
\hline 9 & 7D & 2 & XwPt-7842 & XwPt-7368 & 4.3 & 2 & $0-13$ & 3.0 & $\ldots$ \\
\hline Total $R_{\text {adj }}^{2}(\%)^{\mathrm{h}}$ & $\cdots$ & $\cdots$ & $\cdots$ & $\cdots$ & $\cdots$ & $\cdots$ & $\ldots$ & 54.9 & $\cdots$ \\
\hline \multicolumn{10}{|l|}{ ‘Tuareg'/‘Biscay’ $(n=263)$} \\
\hline 1 & $1 \mathrm{Ans}{ }^{\mathrm{i}}$ & 44 & Xwmc0024 & XwPt-3904 & 3.1 & 0 & $29-59$ & 3.1 & $* *$ \\
\hline 2 & $4 \mathrm{~A}$ & 6 & XwPt-5434 & Xwmc0219 & 5.8 & 0 & $0-13$ & 5.8 & $\ldots$ \\
\hline 3 & $4 B$ & 22 & Xwmc0471 & Xwmc0238 & 19.3 & 0 & $7-29$ & 17.3 & $* *$ \\
\hline 4 & $4 \mathrm{D}$ & 2 & Xcfd0071 & Xgwm0129 & 5.2 & 0 & $0-12$ & 5.2 & $\ldots$ \\
\hline 5 & $6 \mathrm{~B}$ & 24 & XwPt-6286 & XP1459-119 & 12.5 & 0 & $18-30$ & 11.8 & $* *$ \\
\hline 6 & $7 \mathrm{~B}$ & 4 & Xwmc0517 & XP2255-118 & 8.2 & 0 & $0-14$ & 8.0 & $* *$ \\
\hline Total $R_{\text {adj }}^{2}(\%)$ & $\cdots$ & $\cdots$ & $\cdots$ & $\cdots$ & $\cdots$ & $\cdots$ & $\cdots$ & 51.3 & $\cdots$ \\
\hline
\end{tabular}

a Major QTL explaining $\geq 10 \%$ of phenotypic variance are shaded.

${ }^{\mathrm{b}}$ Position in centimorgans (cM).

c Closest marker in bold.

d Distance in centimorgans to the next flanking marker.

e The 95\% confidence interval (CI) after Darvasi and Soller (12).

${ }^{f}$ Normalized partial phenotypic variance explained by detected QTL.

g QTL-environment (E) interaction tested for significance (sequentially rejective Bonferroni $F$ test); $* *$ indicates $F$ test significant at $P<0.01$.

${ }^{\text {h }}$ Adjusted phenotypic variance explained by detected QTL (final simultaneous fit) across environments.

i LOD > 3.0 but not significant (ns) according to critical LOD score after 1,000 permutations $(\alpha=10 \%)$.

TABLE 4. Additive effects of resistance alleles separately for the environments and combined for Septoria tritici blotch (percent flag leaf area affected) ${ }^{\mathrm{a}}$

\begin{tabular}{|c|c|c|c|c|c|c|c|c|c|}
\hline \multirow[b]{3}{*}{ QTL number } & \multirow[b]{3}{*}{ QTL designation } & \multirow{3}{*}{$\begin{array}{l}\text { Donor of } \\
\text { resistance }\end{array}$} & \multicolumn{7}{|c|}{ Additive effect of resistance allele $(\%)^{\mathrm{b}}$} \\
\hline & & & \multicolumn{3}{|c|}{2008} & \multicolumn{3}{|c|}{2009} & \multirow[b]{2}{*}{ Combined } \\
\hline & & & FRE & $\mathrm{HOH}$ & OLI & WOH & FRE & OLI & \\
\hline \multicolumn{10}{|c|}{ 'Florett'/'Biscay' $(n=301)$} \\
\hline 1 & QStb.lsa_fb-1A & 'Florett' & -4.1 & -3.3 & $\ldots$ & -0.1 & -1.0 & -3.2 & -2.3 \\
\hline 2 & QStb.lsa_fb-1B & 'Biscay' & -3.2 & -3.9 & $\ldots$ & -0.5 & -0.9 & -4.6 & -2.4 \\
\hline 3 & QStb.lsa_fb-2B & 'Biscay' & -1.1 & -4.4 & $\ldots$ & -1.0 & -3.6 & -4.4 & -2.9 \\
\hline 4 & QStb.lsa $f b-3 B$ & 'Florett' & -2.0 & -12.9 & $\ldots$ & -0.8 & -6.2 & -7.4 & -5.8 \\
\hline 5 & QStb.lsa_fb-4B & 'Florett' & -1.1 & -7.6 & $\ldots$ & -0.7 & -3.5 & -9.2 & -4.5 \\
\hline 6 & QStb.lsa_fb-5B & 'Biscay' & -2.5 & -4.9 & $\ldots$ & -0.6 & -0.6 & -3.5 & -2.1 \\
\hline 7 & QStb.lsa_fb-6D & 'Florett' & -3.4 & -10.2 & $\ldots$ & -0.7 & -2.5 & -9.6 & -5.2 \\
\hline 8 & QStb.lsa_fb-7A & 'Florett' & -6.2 & -3.0 & $\ldots$ & -1.1 & -2.2 & -2.5 & -3.1 \\
\hline 9 & QStb.lsa_fb-7D & 'Biscay' & -2.7 & -3.8 & $\ldots$ & -0.7 & -1.6 & -2.8 & -2.2 \\
\hline Total $R_{\text {adj }}^{2}(\%)^{\mathrm{c}}$ & & $\ldots$ & 15.7 & 49.8 & $\cdots$ & 16.4 & 40.0 & 42.7 & 54.9 \\
\hline \multicolumn{10}{|c|}{ 'Tuareg'/'Biscay' $(n=263)$} \\
\hline 1 & QStb.lsa_tb-1A & 'Biscay' & -0.6 & $\ldots$ & -3.6 & -0.3 & -1.4 & $\ldots$ & -1.5 \\
\hline 2 & QStb.lsa_tb-4A & 'Tuareg' & -1.6 & $\ldots$ & -4.5 & -1.3 & -1.4 & $\ldots$ & -2.2 \\
\hline 3 & QStb.lsa_tb-4B & 'Tuareg' & -3.5 & $\ldots$ & -11.5 & -1.1 & -2.1 & $\ldots$ & -4.0 \\
\hline 4 & QStb.lsa_tb-4D & 'Tuareg' & -2.1 & $\ldots$ & -2.5 & -1.4 & -1.7 & $\ldots$ & -1.9 \\
\hline 5 & QStb.lsa_tb-6B & ‘Tuareg' & -1.1 & $\ldots$ & -6.4 & -1.1 & -4.5 & $\ldots$ & -3.3 \\
\hline 6 & $Q S t b . l s a \_t b-7 B$ & ‘Tuareg' & -0.7 & $\ldots$ & -7.7 & -0.9 & -1.1 & $\ldots$ & -2.6 \\
\hline Total $R_{\text {adj }}^{2}(\%)^{\mathrm{c}}$ & & $\cdots$ & 12.5 & $\cdots$ & 42.1 & 3.4 & 22.4 & $\cdots$ & 51.3 \\
\hline
\end{tabular}

a Major QTL explaining $\geq 10 \%$ of phenotypic variance are shaded. FRE $=$ Freising, $\mathrm{HOH}=\mathrm{Hohenheim}, \mathrm{OLI}=\mathrm{Oberer}$ Lindenhof, and $\mathrm{WOH}=\mathrm{Wohlde}$

${ }^{\mathrm{b}}$ Estimated additive effects (less percent flag leaf infection) in final simultaneous fit of the resistance allele.

c Adjusted phenotypic variance explained by detected QTL in final simultaneous fit in each environment and in the series. 
QTL mapping of 'Florett'/'Biscay' and 'Tuareg'/'Biscay' revealed four and eight QTL with LOD > 3.0 for plant height and nine and six QTL for heading date, respectively. A few of these QTL had a CI similar to that for STB rating (Table 5). The effects of these co-localizing QTL were rather small, with $\mathrm{n} R_{\text {adj }}^{2}$ of 3.8 to $5.3 \%$.

Fivefold cross validation verified six out of nine QTL in the ES compared with the DS in 'Florett'/'Biscay' and all QTL in 'Tuareg'/'Biscay' (Supplementary Table 1).

Individual effects of the two largest QTL per population are shown in Figures 2 and 3. Total data set was divided into four subpopulations, each carrying different alleles of the two major QTL In 'Florett'/'Biscay', the first subpopulation carrying the susceptible allele $(\mathrm{S})$ at both resistance loci had a mean STB rating of $46 \%$ (Fig. 2). The second and third subpopulation carried the resistant allele $(\mathrm{R})$ at $3 \mathrm{~B}$ locus and the $\mathrm{S}$ allele at $6 \mathrm{D}$ locus or vice versa. Mean STB rating was reduced by $10 \%$ in both subpopulations. The fourth subpopulation carrying both resistant alleles reduced STB rating by $20 \%$ compared with the susceptible allele situation. In 'Tuareg'/'Biscay', similar effects were obtained by analyzing the two major QTL for their phenotypic effects (Fig. 3). The maximal difference between the subpopulation having both resistance alleles and that having both susceptibility alleles was smaller, with $13.2 \%$ mean STB rating. The variation within the resistant subpopulations gives the possibility for further phenotypic selection in both wheat populations.

\section{DISCUSSION}

This study was based on multi-environmental field trials of large mapping populations inoculated with M. graminicola isolates. By spray inoculation of the flag leaves, as done in this study, a similar STB differentiation was achieved than by natural infections of 24 cultivars across nine environments (28), indicating that our inoculation method reflects the natural situation. 'Florett' and 'Tuareg' were among the most resistant entries within their progeny. In a companion article including both parents, only one cultivar ('Solitär') was significantly better than 'Florett' and 'Tuareg' (28). The inoculated isolates BAZ 6/1/04 and BAZ 8/8/04 were virulent to all parents in the seedling stage to exclude effects of the isolate-specific Stb6 and Stb15 genes known to segregate in the populations. Results reported here revealed no QTL for STB resistance near the locations of the mentioned genes on chromosomes $3 \mathrm{~A}$ and $6 \mathrm{~A}$ (4).
Genotypic variation for STB was significant in both populations. For 'Tuareg'/'Biscay', however, genotypic variation was much smaller than the effect of environment and G-E interaction, leading to a low heritability. One cause for this might be that the resistance of 'Tuareg' proved to be environmentally rather unstable (28). Because of the high G-E interaction of 'Tuareg'/ 'Biscay', the number of QTL and the effects of the detected QTL might be underestimated. Moreover, the susceptible parent 'Biscay' was less susceptible in this population compared with 'Florett'/'Biscay', a fact that was caused by differing environments, but also reduced genotypic difference of the progeny.

Plant height and heading date may affect STB resistance considerably as reported in literature $(2,18,27,32)$. In our mapping populations, phenotypic correlations between the three traits were significantly low, indicating that only a small number of QTL might interfere between these traits (Table 5). Indeed, only in 'Florett'/'Biscay' was the CI of a QTL on chromosome 2B mapped for plant height directly overlapping with a minor STBresistance QTL. The QTL for heading date on chromosome 2B and the QTL for heading date and plant height on chromosome 3B were mapped in positions neighboring the STB resistance QTL; however, without an overlap of CIs. This is especially important for the QTL on chromosome 3B with its high impact on STB resistance. Accordingly, there is a chance for identifying recombinants that display the QTL for STB resistance but not for unwanted morphological traits. An explanation for the low importance of morphological traits could be that inoculation was done once after latest genotypes' flag leaves had been fully unrolled. Also, we exactly rated the leaf insertion that has been inoculated, not regarding any epidemiological development of the pathogen from leaf to leaf. Additionally, parents were very similar in their plant height and heading date; for example, both populations were fixed for the dwarfing allele $R h t-D 1 b$. In conclusion, achieving precise phenotyping data in field experiments is a challenge in this pathosystem.

The polymorphism rate in both elite populations was low when summarized across DArT, SSR, and AFLP markers. There were, however, considerable differences among marker types. Only 5 and $2 \%$ of analyzed DArT markers could be mapped in 'Florett'/ 'Biscay' and 'Tuareg'/'Biscay', respectively. Polymorphism rate was $\approx 7 \%$ in both populations but many polymorphic DArT markers did not remain in the final map due to clustering. The polymorphism rate of the SSR markers was much higher, with $\approx 30 \%$ due to preselection of those markers highly polymorphic in

TABLE 5. Localization of quantitative trait loci (QTL) with logarithm of odds (LOD) > 3.0 for plant height and heading date coinciding with QTL for resistance to Septoria tritici blotch in two wheat populations (means across environments) ${ }^{\mathrm{a}}$

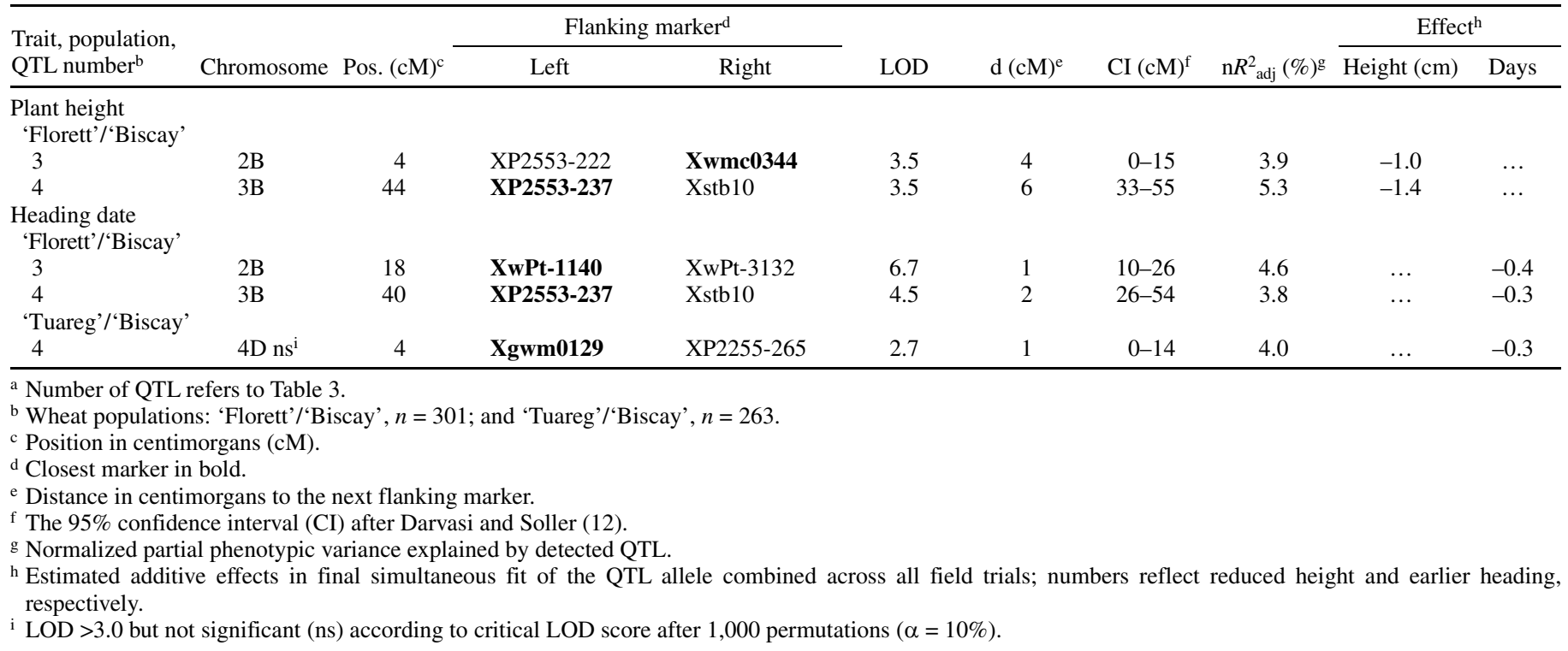


German wheat material (V. Korzun, personal communication). It should be noted that DArT markers for wheat were developed primarily with Australian wheat material. In AFLPs in both populations, only 3 to 4 bands per primer combination were polymorphic compared with 7 to 8 in 'History'/'Rubens' (Holzapfel, personal communication) and, on average, 6.4 in 'Arina/NK93604' (30). Obviously, the resistant, high-yielding elite parents are genetically rather related to the susceptible 'Biscay', although this is not visible from their pedigrees. Genetic similarities $(G S)$ between 'Florett', 'Tuareg', and 'Biscay' were quite high ( $G S=$ 0.70 to 0.73 ), illustrating their relatedness as analyzed by 221 SSR markers scattered evenly across the genome (V. Korzun, personal communication). Pairwise comparisons of other German wheats resulted in a $G S$ of 0.58 in the same analysis. However, the small average interval distances $(2.3$ to $3.6 \mathrm{cM})$ indicate highdensity maps, although genome coverage is limited to $\approx 1,350 \mathrm{cM}$ according to Haldane's mapping function. We had to use this mapping function to fulfill a necessary assumption for CIM (40) although it provides longer maps than the Kosambi function. Somers' high-density consensus map covered 2,569 cM, with an average interval distance of $2.2 \mathrm{cM}$ (33). Taken together, these results indicate that, although a high number of markers have been tested, short maps were achieved because the parents
'Florett', 'Tuareg', and 'Biscay' possess highly conserved genomic regions, most probably due to similarity by descent.

In adult plants, resistance to STB can be isolate-specific or quantitative (15). No known $S t b$ gene is located on chromosomes 1A, 2B, 4B, 4D, and 6D where seven QTL for STB resistance have been found in our populations. Thus, additional sources for STB resistance have been detected here. Three QTL (QStb.lsa_fb-1B, $Q S t b . l s a \_t b-4 A$, and $\left.Q S t b . l s a \_f b-7 A\right)$ were mapped on chromosomes with common markers next to the genes Stb11, Stb12, and $S t b 3$, respectively $(8,9,15)$. Only marker Xwmc0219 next to $S t b 12$ on chromosome 4A was mapped within the CI of QStb.lsa_tb-4A.

Phenotypic data of both mapping populations suggested a typical quantitative inheritance of STB resistance in the field. This was confirmed by QTL analyses, revealing nine and six QTL, respectively, with small individual effects. Altogether, detected QTL in each population explained $>50 \%$ of adjusted phenotypic variance $\left(R_{\text {adj }}^{2}\right)$. Both parents contributed resistant alleles. Major QTL, however, were all from the respective resistant parent. Two QTL per population were declared major, explaining $>10 \%$ of $\mathrm{n} R_{\text {adj. }}^{2}$ This is quite strict in comparison with other QTL studies (31). Major QTL in this study were found consistently across environments on chromosomes $3 \mathrm{~B}$ and $6 \mathrm{D}$ from 'Florett' and 4B and $6 \mathrm{~B}$ from 'Tuareg'.

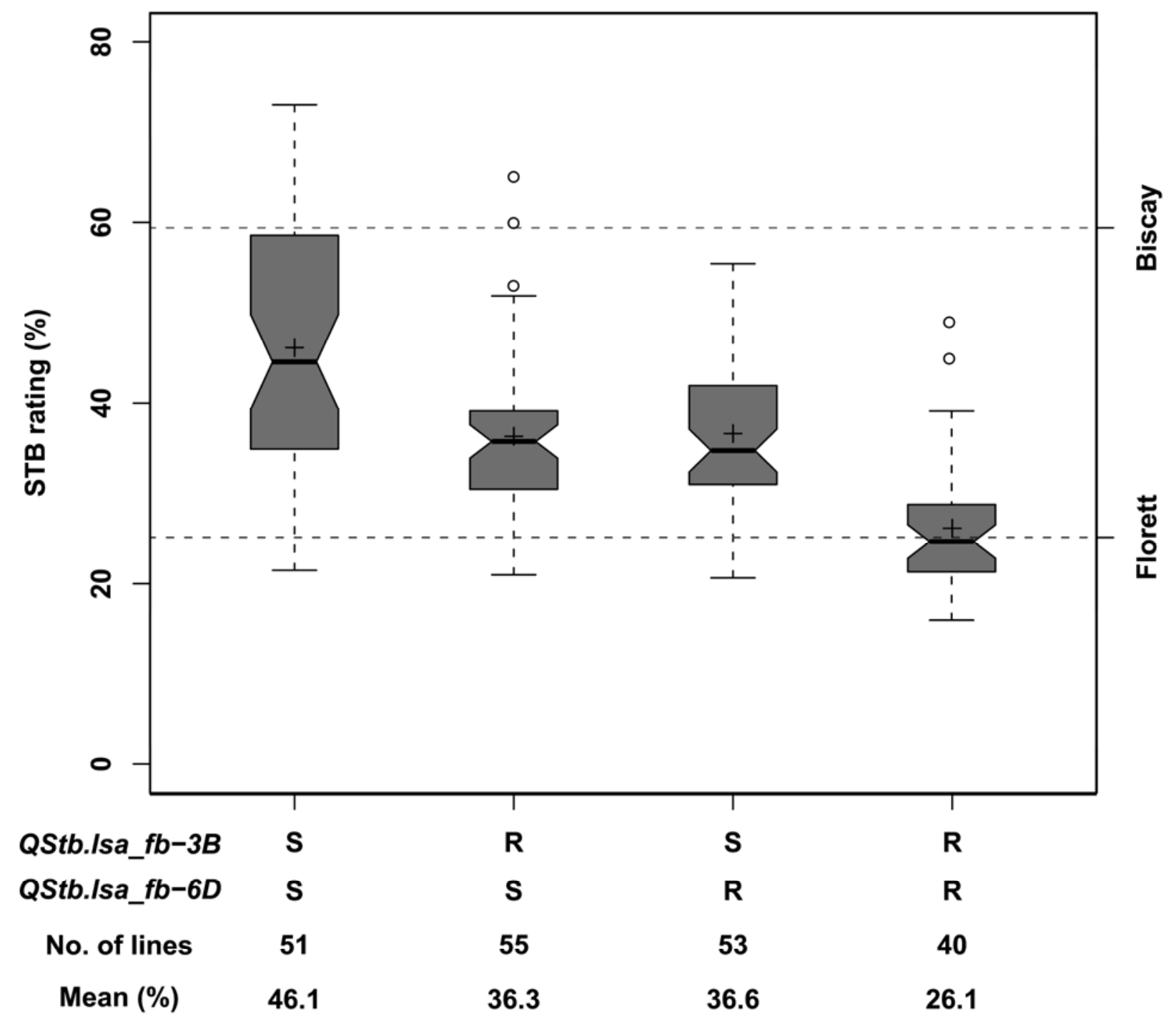

Fig. 2. Notched boxplots for subpopulations of 'Florett'/'Biscay' illustrating four different allele situations at two major quantitative trait loci (QTL) ( $Q S t b . l s a \_f b$ $3 B$ and $-6 D)$ for resistance to Septoria tritici blotch (STB) $(\mathrm{S}=$ susceptible allele present and $\mathrm{R}=$ resistant allele present); if notches do not overlap, medians are different according to McGill et al. (24); horizontal line within boxes = median, $+=$ mean, $o=$ outliers, dashed lines indicate mean STB rating of susceptible and resistant parent, respectively, across environments. 
In two other studies, detection of QTL for STB resistance was reported. Eriksen et al. (13) mapped QTL for STB resistance, with some of the alleles providing resistance at seedling stage, others at adult-plant stage, and some being effective at both stages. Four resistance QTL for adult-plant resistance from the resistant parent 'Senat' were mapped on chromosomes $2 \mathrm{~B}, 3 \mathrm{~A}$, 6B, and 7B (QStb.ris $\phi-2 B, Q S t b . r i s \phi-3 A .2, Q S t b . r i s \phi-6 B .2$, and $Q S t b . r i s \phi-7 B)$, altogether explaining 62 to $77 \%$ of phenotypic variance. There was an overlap of resistance QTL and QTL for plant height at chromosome 3A. In this study, we mapped QTL on the same positions on chromosome $2 \mathrm{~B}$ in 'Florett'/'Biscay' and on chromosomes 6B and 7B in 'Tuareg'/'Biscay'. SSR markers $X w m c 0344$ on chromosome $2 \mathrm{~B}$ close to QStb.lsa_fb-2B and $X w m c 517$ on chromosome 7B close to QStb.lsa_tb-7B were the only markers in accordance to the map of 'Savannah'/Senat. Support intervals of resistance QTL in Savannah/Senat on chromosomes $2 \mathrm{~B}$ and $7 \mathrm{~B}$ did not include the common markers indicating independent QTL. Chartrain et al. (7) detected one QTL from the susceptible parent 'Riband' (QStb.psr-6B-1), explaining 24\% of phenotypic variance $\left(R^{2}\right)$ in one polytunnel experiment. The position of their QTL was close to SSR marker Xgwm0219, which is also present in the 'Tuareg'/'Biscay' population but $\approx 60 \mathrm{cM}$ distal to our QTL on this chromosome. Both previous mapping studies had small population sizes of 65 to 106 progenies affecting the power of QTL detection $(25,29)$.

In summary, adult-plant resistance to $M$. graminicola analyzed in large populations was inherited quantitatively depending on several loci, each explaining only a smaller part of the phenotypic variance. Major QTL described in this study for the first time were found consistently across environments on chromosomes $3 \mathrm{~B}$ and 6D from 'Florett' and 4B and 6B from 'Tuareg'. For providing maximal selection gain in marker-assisted selection (MAS), pyramiding of additively inherited major QTL from different parents in elite breeding populations seems promising (Figs. 2 and 3). Another strategy is to use molecular markers next to effective $S t b$ genes to combine isolate-specific and quantitative resistances. Fine mapping of these QTL with markers common across populations will locate QTL positions more precisely (5), facilitate meta-analysis, and, thus, promote MAS in wheat breeding.

\section{ACKNOWLEDGMENTS}

This project was financially supported by the Bundesministerium für Bildung und Forschung (BMBF, Bonn) via PTJ (Jülich) and the KWS LOCHOW GmbH within the German-French-Spanish ERA-Net PGCEREHEALTH Consortium (project number 0313992A). We thank the

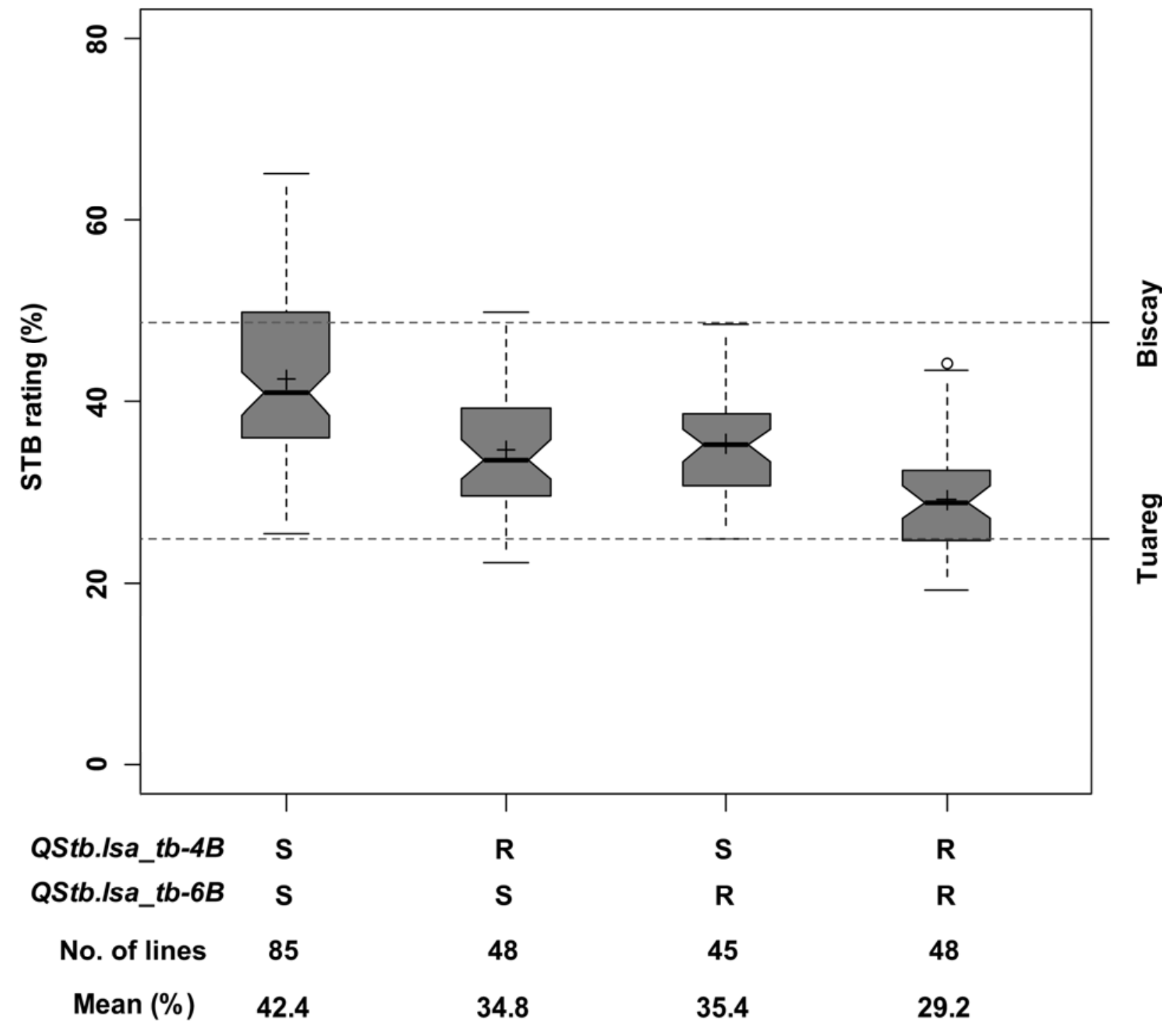

Fig. 3. Notched boxplots for subpopulations of 'Tuareg'/'Biscay' illustrating four different allele situations at two major quantitative trait loci (QTL) ( $Q S t b . l s a \_t b$ $4 B$ and $-6 B$ ) for resistance to Septoria tritici blotch (STB) $(\mathrm{S}=$ susceptible allele present and $\mathrm{R}=$ resistant allele present); if notches do not overlap, medians are different according to McGill et al. (24); horizontal line within boxes = median, $+=$ mean, $o=$ outliers, dashed lines indicate mean STB rating of susceptible and resistant parent, respectively, across environments. 
teams at all locations for their excellent technical assistance in data collection, particularly B. Lieberherr and M. Buck (Universität Hohenheim), L. Giehl and T. Wirth (Institute of Crop Science and Plant Breeding, Freising), and M. Scholz (KWS LOCHOW, Wohlde); and J. Groh (Institute of Crop Science and Plant Breeding, Freising) for providing the AFLP data.

\section{LITERATURE CITED}

1. Akbari, M., Wenzl, P., Caig, V., Carling, J., Xia, L., Yang, S., Uszynski, G., Mohler, V., Lehmensiek, A., Kuchel, H., Hayden, M. J., Howes, N., Sharp, P., Vaughan, P., Rathmell, B., Huttner, E., and Kilian, A. 2006. Diversity Arrays Technology (DArT) for high-throughput profiling of the hexaploid wheat genome. Theor. Appl. Genet. 113:1409-1420.

2. Arraiano, L. S., Balaam, N., Fenwick, P. M., Chapman, C., Feuerhelm, D., Howell, P., Smith, S. J., Widdowson, J .P., and Brown J. K. M. 2009. Contributions of disease resistance and escape to the control of Septoria tritici blotch of wheat. Plant Pathol. 58:910-922.

3. Arraiano, L. S., Brading, P. A., and Brown, J. K. M. 2001. A detached seedling leaf technique to study resistance to Mycosphaerella graminicola (anamorph Septoria tritici) in wheat. Plant Pathol. 50:339-346.

4. Arraiano, L. S., and Brown, J. K. M. 2006. Identification of isolatespecific and partial resistance to Septoria tritici blotch in 238 European wheat cultivars and breeding lines. Plant Pathol. 55:726-738.

5. Asíns, M. J. 2002. Present and future of quantitative trait locus analysis in plant breeding. Plant Breed. 121:281-291.

6. Bohn, M., Khairallah, M. M., González-de-León, D., Hoisington, D. A., Utz, H. F., Deutsch, J. A., Jewell, D. C., Mihm J. A., and Melchinger A. E. 1996. QTL mapping in tropical maize: I. Genomic regions affecting leaf feeding resistance to sugarcane borer and other traits. Crop Sci. 36:13521361.

7. Chartrain, L., Brading, P. A., Widdowson, J. P., and Brown, J. K. M. 2004. Partial resistance to Septoria tritici blotch (Mycosphaerella graminicola) in wheat cultivars Arina and Riband. Phytopathology 94:497-504.

8. Chartrain, L., Berry, S. T., and Brown, J. K. M. 2005. Resistance of wheat line Kavkaz-K4500 L.6.A.4 to Septoria tritici blotch controlled by isolatespecific resistance genes. Phytopathology 95:664-671.

9. Chartrain, L., Joaquim, P., Berry, S. T., Arraiano, L. S., Azanza, F., and Brown, J. K. M. 2005. Genetics of resistance to Septoria tritici blotch in the Portuguese wheat breeding line TE 9111. Theor. Appl. Genet. 110:1138-1144.

10. Chartrain, L., Sourdille, P., Bernard, M., and Brown, J. K. M. 2009. Identification and location of $S t b 9$, a gene for resistance to Septoria tritici blotch in wheat cultivars Courtot and Tonic. Plant Pathol. 58:547-555.

11. Churchill, G. A., and Doerge, R. W. 1994. Empirical threshold values for quantitative trait mapping. Genetics 138:963-971.

12. Darvasi, A., and Soller, M. 1997. A simple method to calculate resolving power and confidence interval of QTL map location. Behav. Genet. 27:125-132.

13. Eriksen, L., Borum, F., and Jahoor, A. 2003. Inheritance and localisation of resistance to Mycosphaerella graminicola causing Septoria tritici blotch and plant height in the wheat (Triticum aestivum L.) genome with DNA markers. Theor. Appl. Genet. 107:515-527.

14. Eyal, Z., Scharen, A. L., Prescott, J. M., and van Ginkel M. 1987. The Septoria Diseases of Wheat: Concepts and Methods of Disease Management. CIMMYT, Mexico.

15. Goodwin, S. B. 2007. Back to basics and beyond: increasing the level of resistance to Septoria tritici blotch in wheat. Australas. Plant Pathol. 36:532-538.

16. Haldane, J. B. S. 1919. The combination of linkage values and the calculation of distances between the loci of linked factors. J. Genet. 8:299-309.

17. Hospital, F., Moreau, L., Lacoudre, F., Charcosset, A., and Gallais, A. 1997. More on the efficiency of marker-assisted selection. Theor. Appl. Genet. 95:1181-1189.

18. Jlibene, M., Gustafson, J. P., and Rajaram, S. 1992. A field disease evaluation method for selecting wheats resistant to Mycosphaerella graminicola. Plant Breed. 108:26-32.

19. Kema, G. H. J., Annone, J. G., Sayoud, R., Van Silfhout, C. H., Van Ginkel, M., and de Bree, J. 1996. Genetic variation for virulence and resistance in the wheat-Mycosphaerella graminicola pathosystem I. Interactions between pathogen isolates and host cultivar. Phytopathology 86:200-212.

20. Kema, G. H. J., and van Silfhout, C. H. 1997. Genetic variation for virulence and resistance in the wheat-Mycosphaerella graminicola patho- system III. Comparative seedling and adult plant experiment. Phytopathology 87:266-272.

21. KeyGene 2008. Standard list for AFLP primer nomenclature. Online publication. http://wheat.pw.usda.gov/ggpages/keygeneAFLPs.html

22. Knapp, S. J., Stroup, W. W., and Ross, W. M. 1985. Exact confidence intervals for heritability on a progeny mean basis. Crop Sci. 25:192-194.

23. McDonald, B. A., and Linde, C. 2002. Pathogen population genetics., evolutionary potential., and durable resistance. Annu. Rev. Phytopathol. 40:349-379.

24. McGill, R., Tukey, J. W., and Larsen, W. A. 1978. Variations of box plots. Am. Stat. 32:12-16.

25. Melchinger, A. E., Utz, H. F., and Schön, C. C. 2004. QTL analyses of complex traits with cross validation., bootstrapping and other biometric methods. Euphytica 137:1-11.

26. Risser, P. 2010. Mapping of quantitative-trait loci (QTL) for adult-plant resistance to Septoria tritici in five wheat populations (Triticum aestivum L.). Ph.D. thesis, University of Hohenheim, Germany. Online publication. http://opus.ub.uni-hohenheim.de/volltexte/2010/517/.

27. Rosielle, A. A. 1972. Sources of resistance in wheat to speckled leaf blotch caused by Septoria tritici. Euphytica 21:152-161.

28. Schilly, A., Risser, P., Ebmeyer, E., Hartl, L., Würschum, T., Reif, C. J., and Miedaner, T. 2010. Stability of adult-plant resistance to Septoria tritici in 24 European winter wheat varieties across nine environments. J. Phytopathol. 159:411-416.

29. Schön, C. C., Utz, H. F., Groh, S., Truberg, B., Openshaw, S., and Melchinger, A. E. 2004. Quantitative trait locus mapping based on resampling in a vast maize testcross experiment and its relevance to quantitative genetics for complex traits. Genetics 167:485-498.

30. Semagn, K., Bjørnstad, Å., Skinnes, H., Marøy, A. G., Tarkegne, Y., and William, M. 2006. Distribution of DArT, AFLP, and SSR markers in a genetic linkage map of a doubled-haploid hexaploid wheat population. Genome 49:545-555.

31. Semagn, K., Skinnes, H., Bjørnstad, A., Maroy, A. G., and Tarkegne, Y. 2007. Quantitative trait loci controlling Fusarium head blight resistance and low deoxynivalenol content in hexaploid wheat population from 'Arina' and NK93604. Crop Sci. 47:294-303.

32. Simón, M. R., Worland, A. J., and Struik, P. C. 2004. Influence of plant height and heading date on the expression of the resistance to Septoria tritici blotch in near isogenic lines of wheat. Crop Sci. 44:2078-2085.

33. Somers, D., Isaac, P., and Edwards, K. 2004. A high-density microsatellite consensus map for bread wheat (Triticum aestivum L.). Theor. Appl. Genet. 109:1105-1114

34. Torriani, S. F. F., Brunner, P. C., McDonald, B. A., and Sierotzki, H. 2009. QoI resistance emerged independently at least 4 times in European populations of Mycosphaerella graminicola. Pest Manage. Sci. 65:155162.

35. Utz, H. F. 2003. PLABSTAT: A computer program for statistical analysis of plant breeding experiments. Stuttgart, Germany, Institute of Plant Breeding, Seed Science, and Population Genetics, University of Hohenheim. Online publication. https://www.uni-hohenheim.de/plantbreeding/ software/plabstat/plabstat_manual_eng.pdf

36. Utz, H. F., and Melchinger, A. E. 1996. PLABQTL: A program for composite interval mapping of QTL. J. Agric. Genomics 2:1-5.

37. Utz, H. F., Melchinger, A. E., and Schön, C. C. 2000. Bias and sampling error of the estimated proportion of genotypic variance explained by quantitative trait loci determined from experimental data in maize using cross validation and validation with independent samples. Genetics 154:1839-1849.

38. Van Ooijen, J. W., and Voorrips, R. E. 2001. JoinMap 3.0., Software for the calculation of genetic linkage maps. Plant Research International, Wageningen, The Netherlands. Online publication. http://www.generationcp.org/capcorner/chile_wksp_2005/manuals/manual_03.pdf

39. Zadoks, J. C., Chang, T. T., and Kunzak, C. F. 1974. Decimal code for growth stages of cereals. Weed Res. 14:415-421.

40. Zeng, Z.-B. 1993. Theoretical basis for separation of multiple linked gene effects in mapping quantitative trait loci. Proc. Natl. Acad. Sci. USA 90:10972-10976.

41. Zhan, J., Pettway, R.E., and McDonald, B. A. 2003. The global genetic structure of the wheat pathogen Mycosphaerella graminicola is characterized by high nuclear diversity, low mitochondrial diversity, regular recombination, and gene flow. Fungal Genet. Biol. 38:286-297.

42. Zwart, R. S., Thompson, J. P., Milgate, A. W., Bansal, U. K., Williamson, P. M., Raman, H., and Bariana, H. S. 2010. QTL mapping of multiple foliar disease and root-lesion nematode resistances in wheat. Mol. Breed. 26:107-124. 